\title{
Factors Affecting the Acceptance and Functioning of Foreign Subsidiary Performance: Examining Environmental Conditions and Corporate and Ethical Legitimacy
}

Mohammad Ali Abdolvand and Maryam Jaberi*

Department of Executive Management, Science and Research Branch, Islamic Azad University, Tehran, Iran

\begin{abstract}
The main objective of this research was to investigate the factors affecting the acceptance and performance of foreign subsidiaries companies considering the environmental conditions and the corporate practical and Corporate Social Responsibility (CSR) of the companies. This research is applied in terms of purpose and descriptive-survey method in terms of implementation. In order to conduct this research, 384 questionnaires were distributed among members of the population including those who purchased foreign brands through stratified random sampling. Out of these questionnaires, 353 questionnaires were collected and entered into the software. The software used in this research is SPSS and PLS software. The results showed that understanding protection of domestic brands influences foreign brand acceptance, foreign brand acceptance affects the performance of foreign brands, local conditions affect the performance of foreign brands, and the acceptance of foreign brands affects the relationship between the importance of understanding the protection of the domestic brands and foreign brand performance Moreover, the results of the research showed that brand practical legitimacy mediates the relationship between the importance of understanding the protection of domestic brands and foreign brand acceptance, but CSR cannot have a mediating role in the relationship between the importance of understanding the protection of domestic brands and the acceptance of the foreign brand.
\end{abstract}

Keywords: Companies performance; Environmental conditions; Foreign subsidiary; Practical legitimacy; Corporate Social Responsibility (CSR)

\section{Introduction}

The activity of foreign brands in every country is generally associated with some problems that make it difficult for these companies to be present in other countries' markets. In Iran, many restrictive laws have been passed for foreign brands, making the activities of such companies within the country subject to certain conditions. For example, according to the head of the Department of Business and Merchants Affairs (according to www.farsnews.com), every foreign producer (home appliances), which wants to represent his brand in Iran, in the first year, must produce a portion of the goods it imports using the capacity of domestic factories in Iran. In addition to the restrictive rules that exist for foreign brands, among many domestic consumers, there is a kind of opposition towards foreign commodities leading them to turn to domestic goods and support domestic production. All of this has led foreign companies often to bear extra costs when doing business abroad. In this research, we will examine whether foreign companies are able to overcome some of these problems.

\section{Problem statement}

Foreign companies often incur additional costs when doing business abroad [1]. This problem, previously referred to as Liability of Foreignness (LOF), is: "All additional costs incurred by an active company in the overseas market, which a local company does not bear" [2]. LOF can be derived from a variety of sources, such as spatial distance, lack of familiarity with the local environment or discriminatory behavior of local stakeholders [2]. Eden and Miller [3] categorized LOF into three categories of risks:

1. The risk of not being familiar with the local business and the lack of international experience.

2. The risk of lack of trust.
3. Risk of discrimination due to patriotic tendencies and host state.

Producers or consumers often perceive that a foreign company has no local legitimacy $[3,4]$ because they consider powerful foreign companies as a threat to development of technology and industry in their own countries [5]. Previous studies have shown that it is possible to overcome additional costs by using the advantages of foreign companies $[2,6]$.

Several studies have looked at how foreign companies can respond to the challenge of LOF and offer suggestions to overcome it, such as selecting a mode of entry [3,7], the use of local managers in decision making [8], learning about the local environment and adapting to the environment [9], offering more product diversity and joining a business group [10] and the acquisition of market-based resources at the host site, such as skilled staff and so on [11]. Overall, these studies point that the risks associated with the non-acceptance of a foreign company are usually during the time when they gain market knowledge and gain local experience in a particular location [12]. However, the risks of discrimination because of discriminatory behavior by local stakeholders remain a major concern for multinational corporations $[1,12]$. In this thesis, we focus on the dangers of discrimination that

*Corresponding author: Maryam Jaberi, Ph.D. Student, Department of Executive Management, Science and Research Branch, Islamic Azad University, Tehran, Iran, Tel: +98-4486517982; E-mail: jaberi.maryam@gmail.com

Received September 07, 2017; Accepted September 20, 2017; Published September 30, 2017

Citation: Abdolvand MA, Jaberi M (2017) Factors Affecting the Acceptance and Functioning of Foreign Subsidiary Performance: Examining Environmental Conditions and Corporate and Ethical Legitimacy. J Account Mark 6: 254. doi: 10.4172/2168-9601.1000254

Copyright: (C) 2017 Abdolvand MA, et al. This is an open-access article distributed under the terms of the Creative Commons Attribution License, which permits unrestricted use, distribution, and reproduction in any medium, provided the original author and source are credited. 
foreign companies may suffer and examine the ways that may be effective to overcome this type of LOF.

Based on the discussion above, the focus of this study is to examine whether foreign brands are able to overcome the LOF that stems from Perceived Importance of Supporting Domestic Retailers (PISDs). In this study, we focus on two mechanisms that can reduce LOF i.e., practical legitimacy and CSR.

In the field of international brands, local consumers expect foreign brands to provide better conditions, such as a good range of products, lower prices and easy access [13]. These aspects provide various direct benefits to consumers. Therefore, they are the core of executive actions that retailers need to advance in order to achieve practical legitimacy [13]. On the other hand, a company cannot rely solely on practical legitimacy for long-term survival. It must also gain CSR, which is judged according to whether the company's actions are in accordance with the welfare of the community [14]. Using CSR, which includes company measures to protect and improve corporate profits and the welfare of the community, the corporate legitimacy of a company is improved.

\section{Review of literature}

Here is a brief explanation of each component of the model.

Perceived importance of supporting domestic (PISD): Recently, Marwiama and Wu [15] proposed an extension of the idea of Shimp and Sharma [16] by defining the concept of PISD retailers. PISD (much like the $\mathrm{CE}$ ) is a reflection of bigot towards foreign companies, which derives from the perception of consumers that foreign companies lack moral legitimacy. The definition of PISD differs from the CE; since the latter emphasizes collective behavior rather than the individual perception of consumers.

In contrast, PISD is heavily focused on another fundamental issue, namely, whether consumers are actually aware of "domestic support". It is possible that even if a person strongly agrees that it is not appropriate for locals to buy foreign products or to visit foreign brands stores; when there is no desire or awareness to support domestic brands, this belief may not affect the actual behavior of the choosing the shop. Therefore, PISD, which indicates interest or willingness to support domestic brands, believes it to be closer to consumer behavioral decisions.

Marwiama and $\mathrm{Wu}$ [15] found that PISD had a negative effect on consumer's choice of foreign brands. In this study, we consider PISD as a discrimination LOF threat and examine how foreign brands operating in the Iranian market can reduce this weakness.

We used one item to calculate PISD. Respondents are asked to give a score based on a 5-point scale, in which 1 means "not important at all" and 5 means "very important" to provide support for domestic brands. Although, generally speaking, the use of an item is not common in market research, methodological literature shows that when subjects and attributes are interconnected (that is, they are conceived as easily and uniformly), the use of a measure of measurements is acceptable and rational rather than a few measures [17].

Corporate Social Responsibility (CSR): The main issue of CSR is that a company is not only obliged to protect and improve its interest in the organization, but also is responsible for the community. However, CSR does not have a unified definition [18]. In a frequently-mentioned study, CSR was divided into four sections: economic, law, ethics, and altruism [19]. He portrays that the essential role of organizations in the production of goods and services and the creation of profits is acceptable (economic responsibility) that is in accordance with the laws and regulations (legal liability). After that the businesses must be proper, fitting and fair (ethical responsibility) and good citizen-company (altruism responsibility) [19]. Among the four types of responsibilities, economic and legal responsibilities are the cornerstone of CSR, which is usually taken by the community. Therefore, many existing studies mainly discuss CSR practices with a higher level of responsibilities (ethical and altruistic responsibility) [18], which is a major concern in our study.

Superior retail mix: For retail mix, we considered the list of store features according to the lists provided in previous studies, such as Pan and Zin Khan [20]. All items were measured on a scale of 5 values in which 1 means "not at all important" and 5 means "very important". This list includes: vendor services, the relationship between vendors, quick product review, possibility of product return, product novelty, product quality, product security, beauty inside the store, the atmosphere inside the store, interior design, access to store products, introduction to the store, convenient product search in the store, product diversity, the number of copies of each product type, repeated sales promotion activities, purchase with a free product and present membership card.

Selecting a foreign brand store: This concept is quite clear referring to the point how much an individual uses a foreign brand name to buy a home appliance. We used one item to calculate this concept. Respondents were asked to score based on a 5-point scale, in which 1 means "I never use" and 5 means "I always use" to the extent they use a foreign brand from a foreign brand store.

Brand performance: Brand performance means the brand's success in the market. Brand awareness, brand image, and brand loyalty have been introduced as indices for brand performance [21]. In a study entitled "Integrated marketing communication and brand performance", Luxton et al. [22] showed that these capabilities have a positive and significant relationship with brand performance. On the other hand, in a study titled "Is the domestic branding effect on performance measured?" Erkmen and Hancer [23] measured customer responses to brand protective-behaviors employee showed that brand citizenship behavior has a positive and significant effect on brand performance. In a study entitled "Brand Identity Management (BIM) and Brand performance: An empirical study of UK IT services company," Coleman et al. [24] showed that the factors related to BIM of the organization including the emphasis on employees and customers, the apparent identity of the organization, brand personality, and human resource activities have a positive and significant relationship with brand performance. Moreover, in a study entitled "The importance of brand identity in business management: A case study of the British banking industry, Buil et al. [25] showed that brand commitment has a positive and significant relationship with brand performance. In a study entitled "The role of brand communication on the beliefs, behavior and performance of frontline employees," Baker et al. [26] showed that the information that customers receive directly from front line employees leads to increased brand awareness and internalization of the value of the brand by them.

Environmental conditions: Environmental conditions include economic, social, legal, business, and spatial areas. These factors can affect the acceptance or non-acceptance of a brand, brand perceptions, brand value, and many brand-related components. In fact, environmental conditions speak of the degree of readiness of people in the field of brand acceptance. 


\section{Importance of the subject}

The existence of foreign brands of home appliances in the country is undeniable. It is also clear that these brands are among the domestic consumers with a high market share. In the meantime, the question that has been posed is how these companies have been able to overcome their foreign obligations and succeed in the Iranian market. The answer to this question can design a model for domestic brands and help them succeed in foreign countries as a foreign brand with foreign obligations.

\section{Research hypotheses and conceptual model}

Research hypotheses include (Figure 1):

1. PISD affects foreign brand acceptance.

2. The practical legitimacy has a mediating role in the relationship between PISD and the acceptance of the foreign brands.

3. CSR has a negative effect on the relationship between PISD and the acceptance of the foreign brand.

4. Foreign brand acceptance affects foreign brand performance.

5. Local conditions affect the performance of the foreign brand.

6. External brand acceptance affects the relationship between PISD and the performance of the foreign brand.

\section{Materials and Method}

\section{Population and sampling}

The population in this research is all customers of foreign brands in the home appliance industry in Tehran. Given that the number of these people is unlimited, according to the Morgan table, it can be noted that the number of samples examined in this study is 384 people. Sampling method in this research is a random-stratified method. Thus, by dividing Tehran into 5 regions of north, south, east, west, and center, and distributing 77 questionnaires in each region, stratified sampling is performed.

\section{Data collection method}

Data collection method in this study is through field and library methods. In the library method, by referring to the previous articles and collecting information, the subject literature and the research background were completed. Moreover, the questionnaire of this research was designed using the library method and data was collected through the field method. In this research, for assessing PISD and foreign brand acceptance, each containing a single item, and for measuring the variables of practical legitimacy, which has 18 questions and CSR, with includes 4 questions, the terms proposed by Maruyama and $\mathrm{Wu}$ [15], and the foreign brand performance and local conditions, each containing 5 questions were used from the points proposed by Hsu et al. [27].

\section{Research method and data collection tool}

The present research is applied based on the purpose and outcome, for conducting which a survey method is used. In addition, as for the measurement of the assumptions relation measurement is used, it can be said that the method of research is a correlation method. A standard questionnaire was used to collect the data. The validity of the questionnaire was assessed by means of CVR and CVI content validity indexes and distribution of questionnaires among 15 experts. The results obtained showed that the validity of the questionnaire was desirable, and to verify the reliability of the questionnaire, 30 questionnaires were distributed among the members of the population. Cronbach's alpha was calculated for each of the variables. The results of the calculations showed that all variables have Cronbach's alpha greater than 0.7. In addition, Kaiser-Meyer-Olkin (KMO) and Bartlett's Test indices were calculated. KMO for all variables in the study was greater than 0.7, and the significance level of the Bartlett's Test was less than 0.05. Therefore, based on this study, Structural Equation Model (SEM) software can be used. The software used in this research was PLS software because in determining the normality of the data with the help of kurtosis and skewness, it was determined that the data is not normal. Therefore, covariance-based software cannot be used, and so it is necessary to use a category of variance-based software that is not sensitive to normality of data, such as the Smart PLS family. Structural Equation Software, unlike regression methods, in structural equation modeling, not only the structural model is measured (the assumed causality between a set of dependent and independent constituents), but also the measurement model (factor loading of the observed points items on the latent variables) are checked. Thus, one can remove items that are not useful in the categories. In principle, the method for analyzing data in this study was the structural equation method, which was done through PLS software. Structural equation modeling involves a number of statistical methods for estimating a network of causal relationships, which is defined, based on a theoretical model, and connects two or more complex hidden concepts, each of which is measured by a number of observable indicators. The purpose of the structural equation modeling analysis is to determine if the theoretical model is supported by sample data. Through structural equations, general hypothesis structures or causal patterns can be verified with non-experimental data.

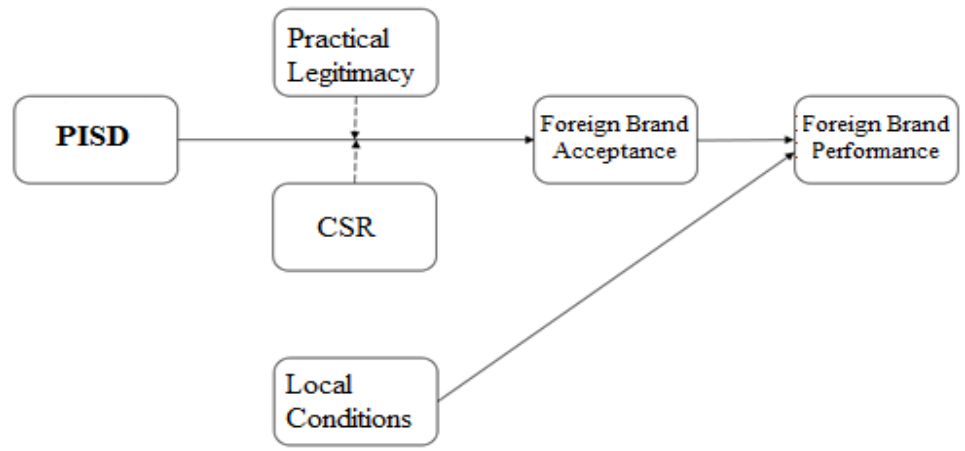

Figure 1: Conceptual model of research $[15,27]$. 


\section{Research Findings}

In order to investigate the research hypotheses with the help of PLS software, the model of measurement and the structural model of the research should be investigated, so that one can reject or confirm the research hypotheses.

\section{Reviewing the measurement model}

To study the size model, the homogeneity of research questions, structural validity, and divergent validity of the measurement model should be investigated. If all the examined indicators are commensurate with the limits defined, one can examine the structural model.

\section{Homogeneity of research questions}

At this stage, all observable variables must have a factor loading greater than 0.7 , and should be eliminated from the research questions if it is less than 0.7 observable and latent variables. According to the Figure 2 below, it can be said that none of the research questions need to be eliminated (initial studies are carried out without the presence of moderators since the moderator is introduced into the model as an auxiliary variable and should not be included in the general analysis).

\section{Examining structural validity}

As there was no need to modify the basic model, the validity of the construct can be evaluated. In construct validity study, the following three conditions are required: First, composite reliability (CR) should be greater than 0.7. Second, the average extraction variance (AVE) should be greater than 0.5 , and the third CR should be greater AVE. According to Table 1, one can examine these indices.

\section{Examining divergent validity}

In order to investigate the divergent validity of the research questions, the Forner Larker criterion is examined. In the Forner Larker criterion, the extracted squared variance average of each question is compared with the correlation of the questions of each variable to the other variable, and if the square of AVEs is larger than the correlation of the variable questions with other variables, this criterion is confirmed (Table 2).

\section{Structural model}

In order to investigate the hypotheses of the research, the structural model is presented. In the structural model, the numbers that are among the latent variables are called path coefficient. The path coefficients of the numbers are between -1 and 1 , and to confirm and reject the hypotheses, we must examine the structural model in the meaningful state of the coefficients. If the numbers on the arrows between the variables are placed outside the interval (-1.96 and 1.96), then the hypothesis is confirmed and otherwise the hypothesis is rejected

As is seen in the Figures 3 and 4, the statistical value of the paths is obtained. To confirm a hypothesis at $95 \%, 99 \%$ and $999 \%$, the least $\mathrm{t}$ values required are $1.96,2.52$, and 3.32 , respectively. In order to examine the hypotheses with moderating variables, with the inclusion of the individual moderating variables into the model, we can confirm or reject research hypotheses.

The study of the hypothesis of CSR shows a negative effect on the relationship between PISD and the acceptance of the foreign brand. Investigating this hypothesis shows the moderating of practical legitimacy in the relationship between PISD and the acceptance of the foreign brand.

Given the significance of the relationship between PISD and

\begin{tabular}{|l|c|c|c|}
\hline Variable & AVE & CR & Result \\
\hline PISD & 1 & 1 & Valid \\
\hline Brand acceptance & 1 & 1 & Valid \\
\hline Brand performance & 0.710 & 0.924 & Valid \\
\hline Local conditions & 0.631 & 0.895 & Valid \\
\hline
\end{tabular}

Table 1: Examining construct validity.

\begin{tabular}{|c|c|c|c|c|}
\hline Variable & PISD & $\begin{array}{c}\text { Brand } \\
\text { acceptance }\end{array}$ & $\begin{array}{c}\text { Brand } \\
\text { performance }\end{array}$ & $\begin{array}{c}\text { Local } \\
\text { conditions }\end{array}$ \\
\hline PISD & 1 & -0.328 & -0.501 & -0.441 \\
\hline Brand acceptance & -0.328 & 1 & 0.614 & 0.463 \\
\hline Brand performance & -0.501 & 0.614 & 1 & 0.707 \\
\hline Local conditions & -0.441 & 0.463 & 0.707 & 1 \\
\hline
\end{tabular}

Table 2: Examining divergent validity.

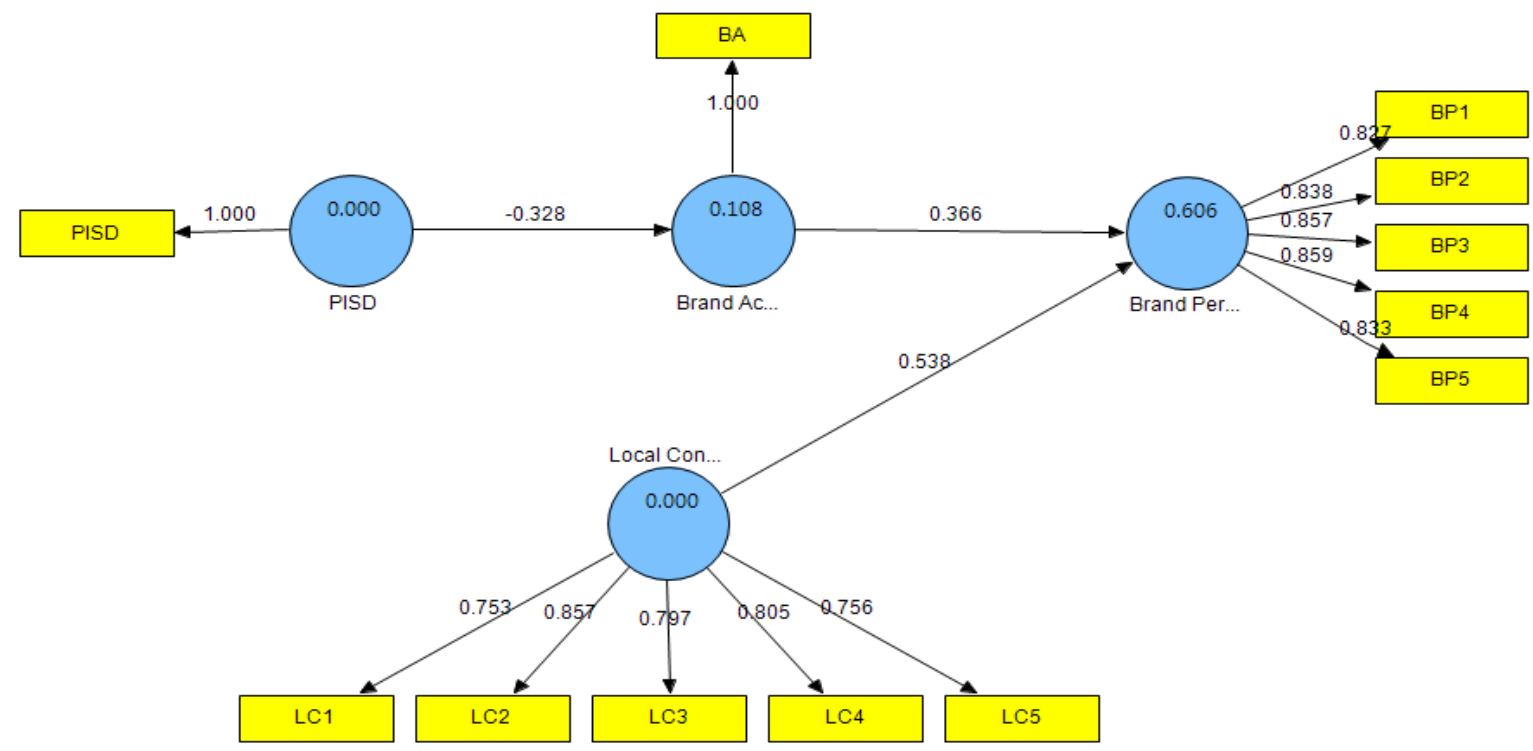

Figure 2: Studying the homogeneity of research items. 


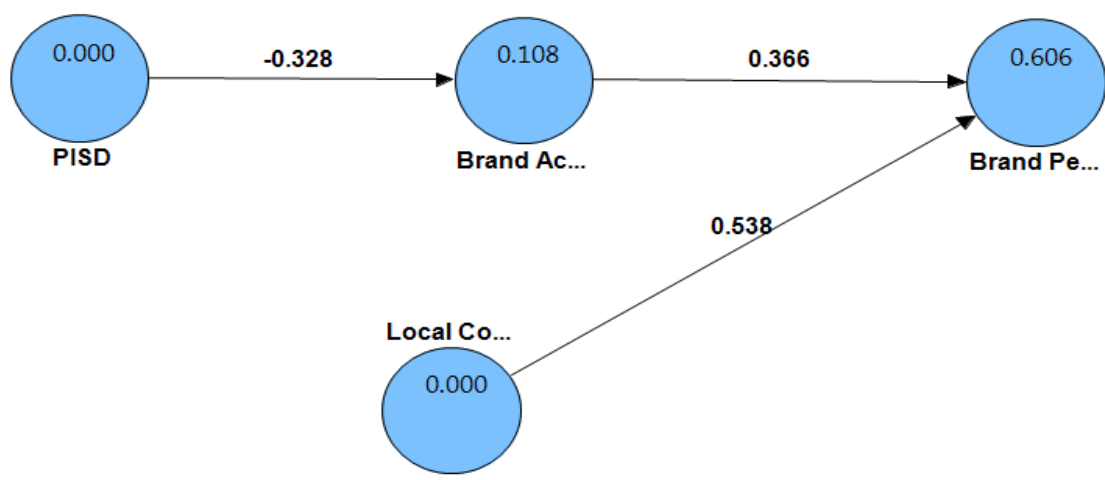

Figure 3: The path coefficients of the research model.

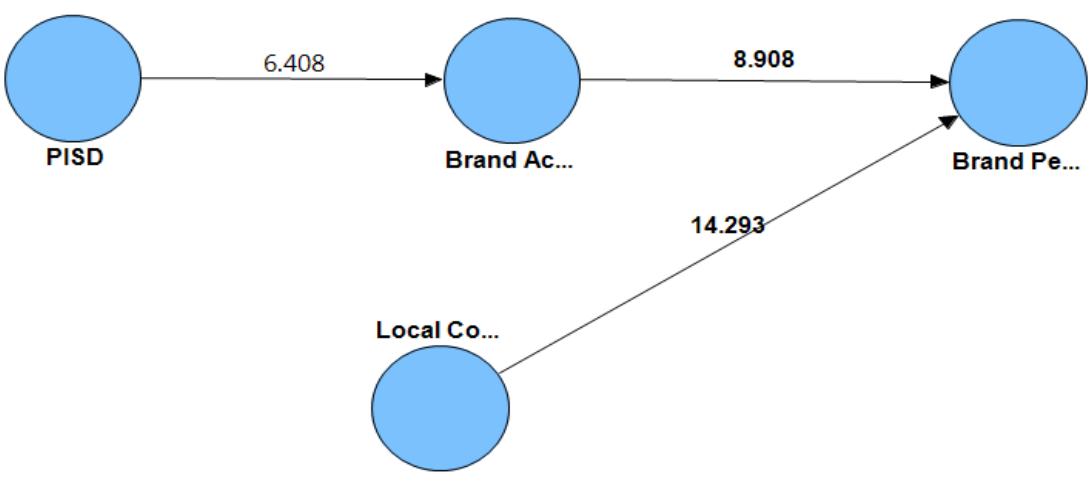

Figure 4: $t$ values for the research model path.

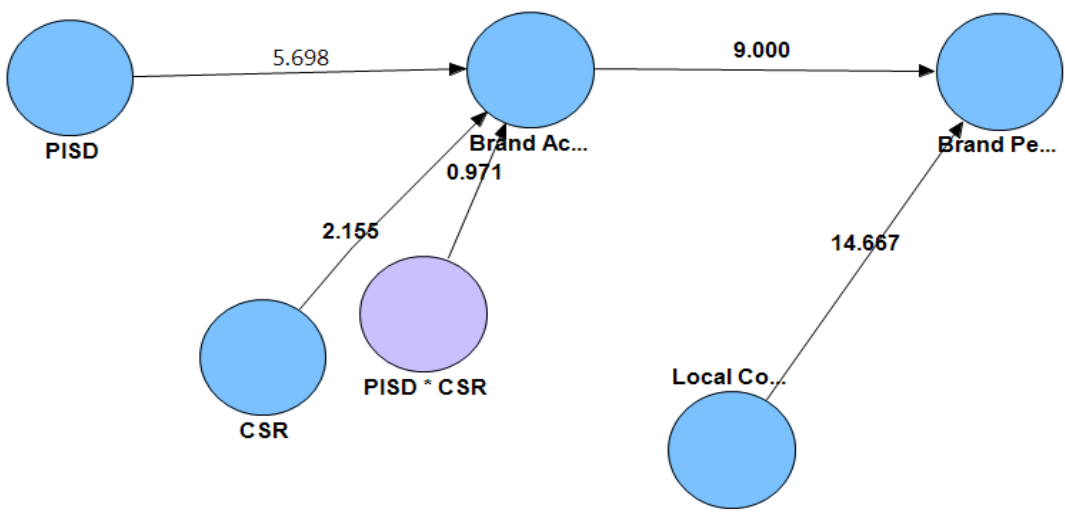

Figure 5: The values of $t$ in the presence of a moderator of variable CSR.

accepting a foreign brand, by entering the moderator variable of practical legitimacy, one can note that this variable moderates the relationship between PISD and foreign brand acceptance. Moreover, given that with moderator's presence and the moderating effect of the negative relationship of the relationship have decreased, it can be stated that the introduction of practical legitimacy can modify the relationship between PISD and the acceptance of the foreign brand (Figures 5-7).

Furthermore, concerning foreign brand acceptance affects the relationship between PISD and the performance of the foreign brand. You should use the Sobel test. Sobel test is known as the product of the coefficient product, delta method, or the normal theory approach. Sobel test is based on the same inference theory used for direct effect to infer about the indirect effect of two variables. The indirect effect of the two variables is a specific sample of indirect effect in the error of two variables that is subject to sampling variance. Sobel test requires the estimation of the error of two variables and its formula is as follows:

$$
s e_{a b}=\sqrt{a^{2} s e_{b}^{2}}+b^{2} s e_{a}^{2}
$$

Finally, the test statistic is obtained using the following formula, which is compared with the number 1.96. If it is greater than 1.96 , the hypothesis is confirmed; and if it is smaller, the hypothesis is rejected.

$$
t=\frac{a b}{s e_{a b}}
$$

In examining the hypothesis of the effect of PISD on the foreign 


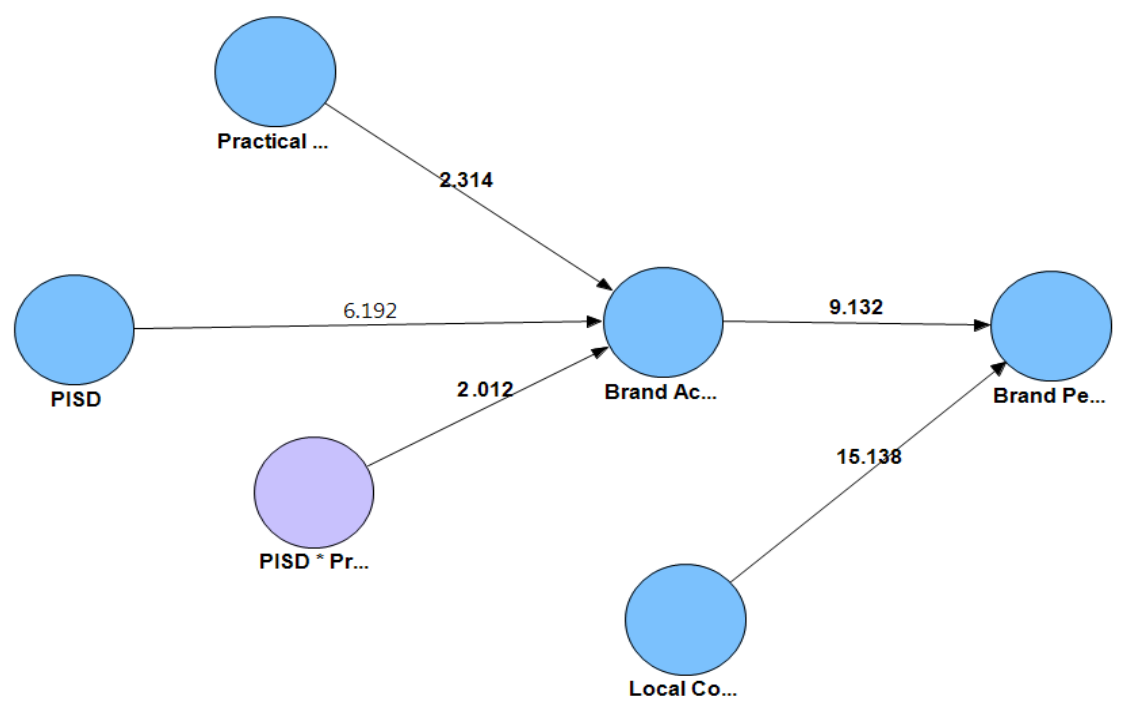

Figure 6: $t$ values in the presence of the moderating variable practical moderator.

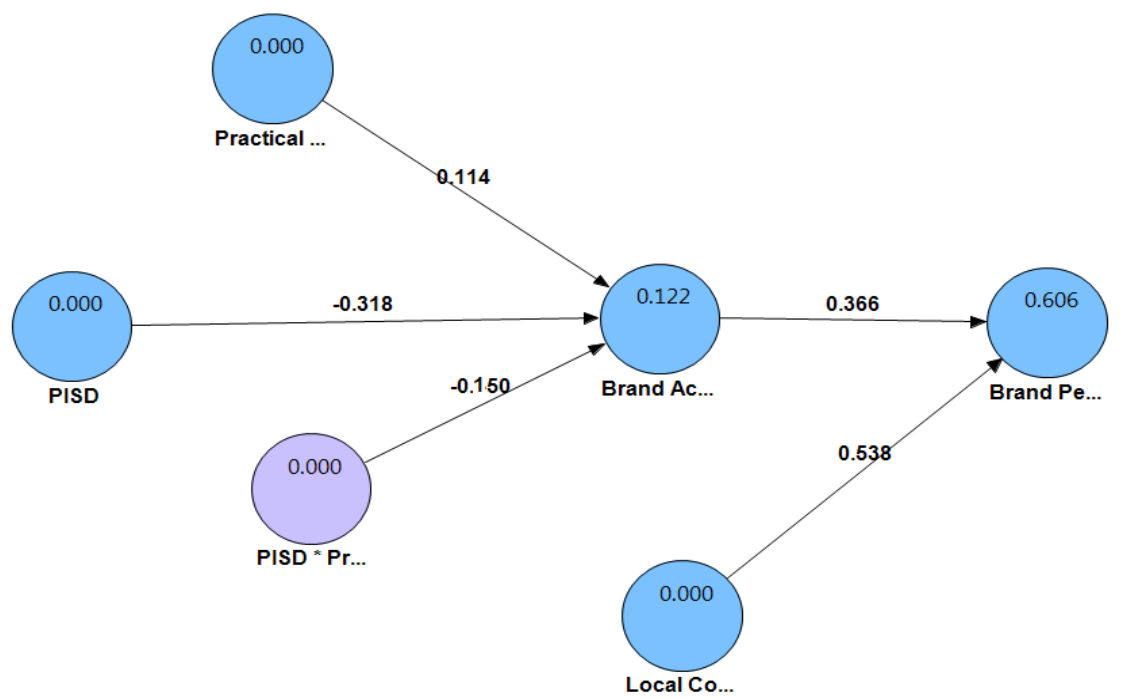

Figure 7: The path coefficient in the presence of the practical variable as a moderator.

brand performance with the mediating role of foreign brand acceptance, the value of $t$ obtained from Sobel test is equal to 5.40 and the coefficient of the indirect path effect of PISD on the foreign brand performance with the mediation of foreign brand acceptance was -0.205 . Therefore, given that $t$ value is out of the range (-1.96 and 1.96), it can be said that this hypothesis is confirmed.

\section{Research Results}

The results of this study showed that all the research hypotheses, except for the hypothesis that examined the relationship between PISD and external brand acceptance by considering the moderating role of CSR was confirmed.

In examining research hypotheses, it was found that PISD is influential on the acceptance of external brands. This hypothesis showed that, as much as customer PISD increase, the acceptance of external brands reduces and buy and use foreign goods less. Thus, it is necessary to think carefully so that everyone understands that they should support domestic brands, for example, massive advertising to support domestic brands. Some factories should be established and start work with the goal of supporting domestic brands, and this should be brought to the notice of all people. Moreover, the results of research hypotheses showed that practical legitimacy can moderate the relationship between supporting domestic brands and external brand acceptance. Thus, by considering the desirable performance of foreign brands, desirable after sales services, and other favorable conditions, which leads to the foreign brand's superiority to the domestic brand, it can be stated that the negative effect of PISD on external brand acceptance decreases and the entry of this variable can show acceptance of the foreign brand along with PISD more justifiable. Therefore, the hypothesis states that the legitimacy of a foreign brand, which includes the possibility of product return and product warranty, product quality and security, store services (vendor services, vendor communication, beauty inside the store, access to store products, shop interior atmosphere, and 
Citation: Abdolvand MA, Jaberi M (2017) Factors Affecting the Acceptance and Functioning of Foreign Subsidiary Performance: Examining Environmental Conditions and Corporate and Ethical Legitimacy. J Account Mark 6: 254. doi: 10.4172/2168-9601.1000254

interior design), variety of products and presentation of membership card, etc., can make the acceptance of the foreign brand more justified by the customer's PISD. Moreover, and as long as the domestic brand cannot provide the conditions that justify the legitimacy of the foreign products, it cannot be expected that foreign goods will not be preferred.

The results also showed that environmental conditions also affect the performance of foreign brands. The environmental conditions include the economic, social, legal, business, and spatial areas, which directly affect the performance of the foreign brand, meaning that, as the legal barrier allows import of imported products; foreign brands' performance will be much more favourable. In addition, if the economic atmosphere of the ruling community allows, people are more inclined to buy foreign brands and the performance of the foreign brand is more favourable. Therefore, it can be stated that environmental conditions have a direct impact on foreign brand performance.

\section{Conclusion}

The studies showed that foreign brand acceptance also affects brand performance. As the foreign brand is accepted better and more in the community, the success rate of the foreign brand is increased, and thus foreign brand can be said to be more desirable. Moreover, the results showed that supporting the domestic brand has a negative and significant effect on foreign brand performance with the mediating role of external brand acceptance. This means that if customers believe that they should support domestic brands, even if they intend to accept foreign brands, one cannot expect a foreign brand to perform well on the market. This hypothesis confirms that if the Iranian buyers believe that domestic brand support is needed, one can expect the purchase of foreign brands reduces and the buyers buy domestic goods more.

\section{References}

1. Hymer SH (1976) International operations of national firms. MIT press.

2. Zaheer S (1995) Overcoming the liability of foreignness. Academy of Management Journal 38: 341-363.

3. Eden L, Miller S (2001) Opening the black box: Multinationals and the costs of doing business abroad. InAcademy of Management Proceedings. Academy of Management 1: C1-C6

4. Denk N, Kaufmann L, Roesch JF (2012) Liabilities of foreignness revisited: A review of contemporary studies and recommendations for future research. Journal of International Management 18: 322-334.

5. Vernon R (1977) Storm over the multinationals: The real issues. Harvard University Press.

6. Nachum L (2003) Liability of foreignness in global competition? Financia service affiliates in the city of London. Strategic Management Journal 24: 1187 1208.

7. Chen $T$ (2006) Liability of foreignness and entry mode choice: Taiwanese firms in Europe. J Bus Res 59: 288-294.

8. Mezias JM (2002) Identifying liabilities of foreignness and strategies tominimize their effects: the case of labor lawsuit judgments in the United States. Strategic Management Journal 23: 229-244.

9. Petersen B, Pedersen $T$ (2002) Coping with liability of foreignness: Differen learning engagements of entrant firms. Journal of International Management 8: $339-350$.

10. Elango B (2009) Minimizing effects of 'liability of foreignness': Response strategies of foreign firms in the United States. Journal of World Business 44: 51-62.

11. Barnard $H$ (2010) Overcoming the liability of foreignness without strong firm capabilities-the value of market-based resources. Journal of International Management 16: 165-176.

12. Miller SR, Parkhe A (2002) Is there a liability of foreignness in global banking? An empirical test of banks' X-efficiency. Strategic Management Journal 23: 55-75.
13. Zarkada-Fraser A, Fraser C (2002) Store patronage prediction for foreignowned supermarkets. International Journal of Retail \& Distribution Management 30: 282-299.

14. Handelman JM, Arnold SJ (1999) The role of marketing actions with a socia dimension: Appeals to the institutional environment. The Journal of Marketing, pp: 33-48.

15. Maruyama M, Wu L (2015) Overcoming the liability of foreignness in international retailing: a consumer perspective. Journal of International Management 21: 200-210.

16. Shimp TA, Sharma S (1987) Consumer ethnocentrism: construction and validation of the CETSCALE. Journal of Marketing Research, pp: 280-289.

17. Fuchs C, Diamantopoulos A (2009) Using single-item measures for construct measurement in management research: Conceptual issues and application guidelines. Die Betriebswirtschaft 69: 195

18. Tian Z, Wang R, Yang W (2011) Consumer responses to corporate social responsibility (CSR) in China. Journal of Business Ethics 101: 197-212.

19. Carroll AB (1991) The pyramid of corporate social responsibility: Toward the moral management of organizational stakeholders. Business Horizons 34: 39-48.

20. Pan Y, Zinkhan GM (2006) Determinants of retail patronage: a meta-analytical perspective. Journal of Retailing 82: 229-243.

21. Yin Wong $H$, Merrilees $B(2008)$ The performance benefits of being brandorientated. Journal of Product and Brand Management 17: 372-383.

22. Luxton S, Reid M, Mavondo F (2015) Integrated marketing communication capability and brand performance. Journal of Advertising 44: 37-46.

23. Erkmen E, Hancer M (2015) "Do your internal branding efforts measure up? Consumers' response to brand supporting behaviors of hospitality employees. International Journal of Contemporary Hospitality Management 27: 878-895.

24. Coleman DA, de Chernatony L, Christodoulides G (2015) B2B service brand identity and brand performance: an empirical investigation in the UK's B2B IT services sector. European Journal of Marketing 49: 1139-1162.

25. Buil I, Catalán S, Martínez E (2016) The importance of corporate brand identity in business management: An application to the UK banking sector. BRQ Business Research Quarterly 19: 3-12.

26. Baker TL, Rapp A, Meyer T, Mullins R (2014) The role of brand communications on front line service employee beliefs, behaviors, and performance. Journal of the Academy of Marketing Science 42: 642-657.

27. Hsu CW, Chen H, Caskey DA (2017) Local conditions, entry timing, and foreign subsidiary performance. International Business Review 26: 544-554. 